Science, Technology and Development 34 (1): 9-15, 2015

ISSN 0254-6418 / DOI: 10.3923/std.2015.9.15

(C) 2015 Pakistan Council for Science and Technology

\title{
Optimization of Process Conditions for Pectin Extraction from Citrus Peel
}

\author{
Maazullah Khan, Nizakat Bibi and Aurang Zeb \\ Nuclear Institute for Food and Agriculture, P.O. Box 446, Tarnab, Peshawar, Pakistan
}

\begin{abstract}
Pectin is a complex polysaccharide and natural food additive extracted from citrus peel and apple pomace in the form of brownish powder. It is widely used as a jelling and thickening agent and the food industry especially in jams and jellies. It is also recommended for use as fat replacer and also lowers blood cholesterol by increasing viscosity in the intestinal tract thus lowering cholesterol absorption. Peel of sweet oranges was chopped to small pieces in a vegetable cutter and dried in an electrical drier to 8-10\% moisture contents. The dried peel was ground and then subjected to pectin extraction using water as solvent. Three treatments with different levels i.e., $\mathrm{pH}\left(1,2,2.5,3,3.5,4,4.5\right.$ and 5), temperature of solvent $\left(70,85\right.$ and $\left.95^{\circ} \mathrm{C}\right)$ and extraction time (0.5, 1, 2, 3, 4 and $5 \mathrm{~h}$ ) were evaluated. Development of an economical processing method for pectin extraction from citrus peel, that offers energetic properties nearly identical to those prepared by other methods (soxhlet method and microwave) using other substrates, is reported. Dried citrus peel contains about $30 \%$ pectin It has been found that $30 \mathrm{~min}$ heating at $70^{\circ} \mathrm{C}$ and $\mathrm{pH}$ level 2.5 resulted in $21 \%$ pectin extraction followed by $1 \mathrm{~h}$ heating at $85^{\circ} \mathrm{C}$ at $\mathrm{pH}$ level 3.0 and a similar pectin yield. Up to $17 \%$ yield was obtained for heating at $95^{\circ} \mathrm{C}$ at $\mathrm{pH}$ level 1 irrespective of the time of heating. It can be inferred from these experiments that $\mathrm{pH}$ range between $2.0-2.5$ and heating at temperature of $70^{\circ} \mathrm{C}$ for 30 min seems to be the most suitable condition for pectin extraction as time and energy efficient process conditions.
\end{abstract}

Key words: Citrus peel, pectin, extraction, purification, characterization

\section{INTRODUCTION}

Pectins are complex polysaccharides mainly composed of 1-4 linked $\alpha$-D-galacturonic acid (Fig. 1) and found in middle lamella of plant cell membrane (Garna et al., 2004).

D-Galacturonic acid is a sugar acid, an oxidized form of D-galactose and is present as polygalacturonic acid in pectin as shown in Fig. 2. It has an aldehyde group at C1 and a carboxylic acid group at C6. Other oxidized forms of D-galactose are D-galactonic acid (carboxylic group at C1) and meso-galactaric acid (mucic acid) (carboxylic groups at $\mathrm{C} 1$ and $\mathrm{C6}$ ). It is also a uronic acid or hexuronic acid.

The non-esterified galacturonic acid units can be either free acids (carboxyl groups) or salts with sodium, potassium or calcium. The salts of partially esterified pectins are called pectinates, if the degree of esterification is below $5 \%$ the salts are called pectates, the insoluble acid form, pectic acid. Some of its galacturonide units are esterified as methyl galacturonate. One of the most important properties of pectin is gelling. The Degree of Esterification (DE) affects the gelling properties of pectin. The structure shown in Fig. 3 has three methyl ester forms $\left(-\mathrm{COOCH}_{3}\right)$ for every two carboxyl groups $(-\mathrm{COOH})$, hence it is has a $60 \%$ degree of esterification, normally called a DE-60 pectin. High Methoxy (HM) pectins have the ability to form gels with sugar and acid, so-called low water activity gels or sugar-acid- pectin gels.

Such a gel is considered as 2-dimensional network of pectin molecules in which the solvent (water) with the co-solutes sugar and acid are immobilized. This results in a system resisting deformation and showing a stress-strain relationship for small deformation. The buildup of the 3-dimensional network is based on the formation of junction zones in which there are chain associations stabilized by hydrogen bonding between undissociated carboxyl and secondary alcohol groups and by hydrophobic interaction between methyl esters. The gelation mechanism of pectin is mainly governed by their Degree of Esterification (DE). For the low methoxyl pectins, denoted LMP ( $\mathrm{DE}<50 \%)$, gelation results from specific non-covalent ionic interactions between blocks of galacturonic acid residues of the pectin backbone and

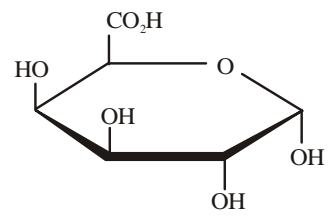

Fig. 1: Structure of pectin 


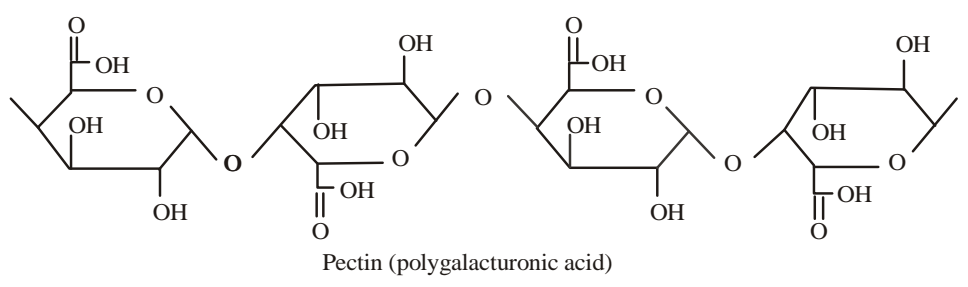

Fig. 2: Structure of polygalacturonic acid

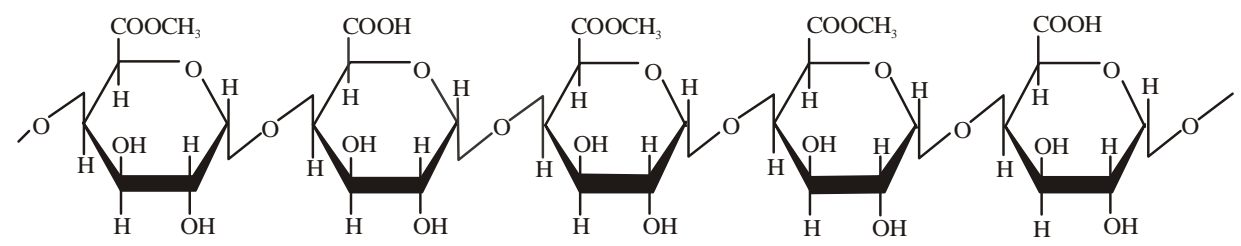

Fig. 3: Pectin a polymer of $\alpha$-galacturonic acid with a variable number of methyl ester groups

with divalent ions such as calcium. The affinity of pectin chains towards calcium is known to increase with decreasing degree of esterification or ionic strength and with increasing polymer concentration. Besides the influence of the charge density of the polygalacturonate chain, the distribution pattern of free and esterified carboxyl groups has an important effect on the strength of calcium binding. Due to this property, pectin has wide applications in a variety of food formulations as jellying and thickening agent. Pectin is a natural food additive used extensively in the food industry as a gelation agent. It is also being recommended for use as fat replacer. The world market demand for pectin is in excess of 30,000 t annually and is growing by about $4-5 \%$ per annum (Garna et al., 2006). On account of its ever-increasing use and demand pectin has become an indispensable ingredient in food industry. Major sources of pectin are apple pomace and citrus peel. Dried citrus peel has about $30 \%$ pectin. The orange peels, if treated as waste materials, may create environmental problems, particularly water pollution, since the presence of biomaterials in orange peels such as peel oil, pectin, as well as sugar, stimulate aerobic bacteria to decompose the biodegradable organic matters into products such as carbon dioxide, nitrates, sulfates and phosphates in water. This problem could be turned into an opportunity, if potentially marketable by products such as pectin could be extracted from the peel. The peel, pectin after extraction, can be used as a high protein stock feed in dry form, increasing the potential return for the orange juice industry and reducing the pollution load to the environment.

The manufacture of pectin typically comprises extraction, purification/concentration and drying. The use of a suitable method for pectin extraction is significant in order to maximize its yield and quality. The literature concerning most commonly used methods for the extraction of pectin includes direct boiling, microwave heating (Garna et al., 2007; El-Nawawi and Shehata, 1987). Nevertheless, none of the methods extract all the pectin without causing some degradation. Microwave heating extraction takes no more than fifteen minutes to extract a satisfactory amount of pectin. However, its commercial application may not be realistic. Production of pectin by enzymes may take up to two days (Donaghy and McKay, 1994). The yield of pectin depends on extraction operation conditions such as temperature, extraction time, $\mathrm{pH}$ and the types of extraction peels (Fishman et al., 1999; Liu et al., 2006). The usual extraction procedure involves the use of water acidified to a $\mathrm{pH}$ between 1 and 4.5 with mineral acid, such as hydrochloric acid, sulphuric acid or nitric acid. The crushed citrus peels are added to this acidified water and then slightly stirred at a temperature between $60-95^{\circ} \mathrm{C}$ for time period ranging from 30 min to several hours. The solid water mixture is subsequently separated by centrifugation or filtration. In the filtrate, the pectin is precipitated with the addition of alcohol. The filtrate is concentrated through evaporation in order to minimize the amount of alcohol used. The isolated pectin is then washed again with alcohol, dried and ground.

Citrus processing industry generates large amount of peel. Major gains for the industry could be the use of the waste to produce value added product, boosting indigenous production of high grade pectin as import substitute and the use of depectinized byproduct in cattle feed. The present study was therefore, undertaken to develop a simple and economical method for pectin extraction. 


\section{MATERIALS AND METHODS}

Chemicals: Sodium chloride, ethanol, phenol red and sodium hydroxide, magnesium sulphate and sulphuric acid, distilled water, acetone and $30 \% \mathrm{w} / \mathrm{w}$ glycerin in water.

Preparation of sample: About 400-500 crates of sweet oranges were purchased from the fruit market in Peshawar. After extraction of juice, the peel was chopped to small pieces in a vegetable cutter and dried in electrical drier to $8-10 \%$ moisture level. The dried peel was ground and then subjected to pectin extraction using water as solvent. Three treatments with different levels i.e., $\mathrm{pH}(1,2,2.5,3,3.5,4,4.5$ and 5), temperature of solvent $\left(70,85\right.$ and $\left.95^{\circ} \mathrm{C}\right)$ and extraction time $(0.5,1,2,3,4$ and 5 h) were evaluated.

Extraction and isolation of pectin from citrus peel: Twenty five gram of dried citrus peel was weighed into a stainless steel jug. It was blended in $1000 \mathrm{~mL}$ distilled water for 2-3 min. The homogenate was transferred to $1500 \mathrm{~mL}$ beaker and the $\mathrm{pH}$ of the mixture was adjusted (1.0-5.0). The flow diagram of the overall process is given in Fig. 4.

Characterization of prepared pectin: Prepared pectin can be characterized and compared with other pectin (commercial and reagent grade) by determination of:

- Methoxy contents

- Acetyl value

- Viscosity

Determination of methoxy contents: The Degree of Methylation (DM) is defined as the percentage of carbonyl groups esterified with methanol. Methoxy content is determined by the saponification of pectin followed by titration of the free carboxyl acid groups:

- $\quad 2.5 \mathrm{~mL}$ of ethyl alcohol and $0.5 \mathrm{~g} \mathrm{NaCl}$ was added to $0.25 \mathrm{~g}$ dried pectin

A yellow solution was obtained after addition of $100 \mathrm{~mL} \mathrm{CO}_{2}$, free distilled water and 6 drops phenol red to the above reaction mixture. Ten milliliter of this solution was titrated with $0.1 \mathrm{M} \mathrm{NaOH}$ till appearance of pink color (V1). Then, $12.5 \mathrm{~mL}(0.25 \mathrm{M}) \mathrm{NaOH}$ was added to the reaction mixture, the solution was shaken, kept for 30 min at room temperature in stoppered flask, titrated against $0.25 \mathrm{M} \mathrm{HCl}$ till the color of solution changed to yellow and again titrated with $0.1 \mathrm{M} \mathrm{NaOH}$ till formation of pink coloration (V2). The volume obtained was used to calculate (\%) methoxy content which is equal to the total mass of methoxy over the mass of the pectin sample multiplied by 100 .

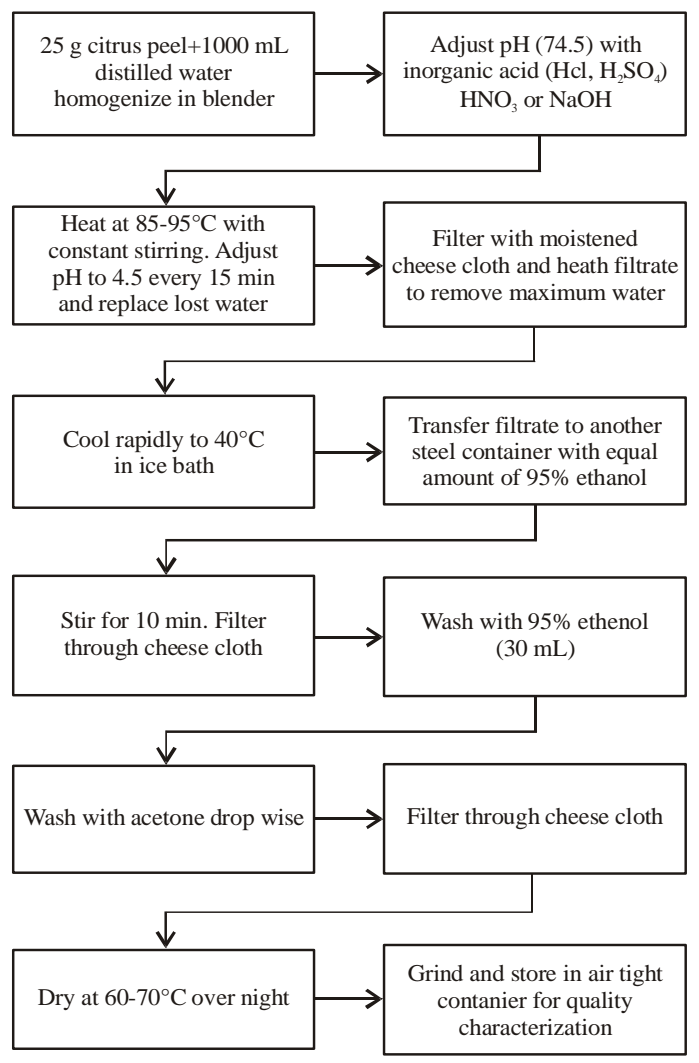

Fig. 4: Flow diagram of the pectin extraction process

Determination of acetyl value: $0.5 \mathrm{~g}$ pectin was weighed into a $250 \mathrm{~mL}$ conical flask and then $25 \mathrm{~mL}$ of $0.1 \mathrm{M}$ $\mathrm{NaOH}$ solution was added. The content was shaken until the pectin was dissolved. It was kept for at least one hr followed by dilution to $50 \mathrm{~mL}$ with distilled water. From this solution, $20 \mathrm{~mL}$ was taken to distillation apparatus and $20 \mathrm{~mL}$ of magnesium sulphate-sulphuric acid solution was added. Steam distillate of $100 \mathrm{~mL}$ was collected and titrated against $0.05 \mathrm{M} \mathrm{NaOH}$ using phenol red as indicator. Acetyl value was calculated with following equation:

$$
\text { Acetyle }(\%)=\frac{\text { Normality of } \mathrm{NaOH} \times \mathrm{mL} \text { of } \mathrm{NaOH} \times 4.3}{\text { Wt of sample }}
$$

Determination of viscosity: The measure of a fluid resistance to flow is termed as its "Viscosity". Fluids can Newtonian (or simple flow) and non-Newtonian (complex flow). Newtonian flow represents an ideal situation, in which viscous liquids obey Newton's law of viscous flow, according to which the flow rate is directly dependent on the applied shearing stress. These liquids are called Newtonian fluids and include most solvents such as water, alcohol, benzene, true solutions and very dilute colloidal solutions. Newtonian fluids exhibit a straight-line relationship 
between shear rate $(\mathrm{G})$ and shear stress $(\mathrm{F})$ and are described in terms of absolute viscosity $(\eta)$ :

$$
F=\eta G
$$

Other fluids do not obey Newton's law of flow and are referred to as non-Newtonian fluids. These fluids do not exhibit a linear relationship between shear rate and shear stress and are usually described in terms of apparent viscosity $\left(\eta_{\text {app }}\right)$.

The instruments used in measuring the flow properties of fluids are called "viscometers or rheometers". Single point instruments, such as a simple capillary viscometer (e.g., Ostwald viscometer) was used for determining viscosity. The Ostwald viscometer has the form of a U-tube. Its use is based on measuring the time required for a liquid to flow between two marks. The viscosity of the liquid in poise or in stokes is then determined using Eq. 2 or 3:

$$
\begin{gathered}
\eta=\mathrm{Kt} \rho \\
\text { Kinematic viscosity }=\mathrm{Kt}
\end{gathered}
$$

where, $\mathrm{K}$ is an instrumental constant, $\mathrm{t}$ is the flow time and $\mathrm{r}$ is the density of the liquid.

Usually, a liquid of known viscosity is compared with another liquid of unknown viscosity, therefore,

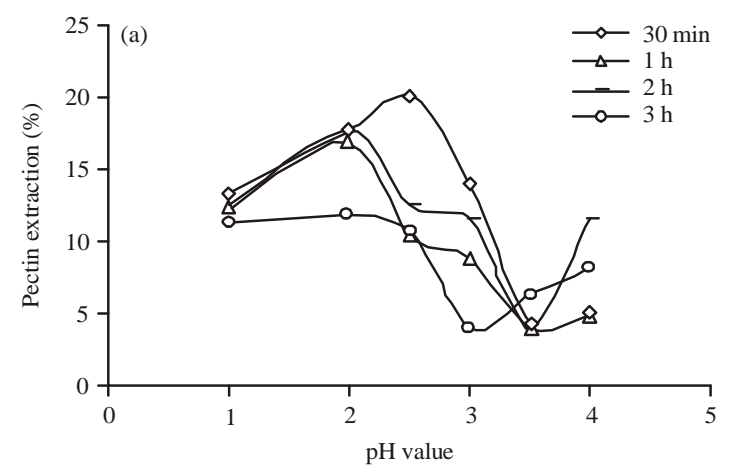

eliminating the necessity for the determination of the instrumental constant as shown in Eq. 4.

$$
\eta_{1} / \eta_{2}=\rho_{1} t_{1} / \rho_{2} t_{2}
$$

\section{RESULTS AND DISCUSSION}

Data comprising pectin isolation using three levels of temperature $\left(70,85\right.$ and $\left.95^{\circ} \mathrm{C}\right)$, three levels of heating time (30 min, 1, 2 and $3 \mathrm{~h}$ ) and eight $\mathrm{pH}$ values (1.0, 2.0, 2.5, 3.0, 3.5, 4.0, 4.5 and 5.0) are summarized in Fig. 5a-c.

As is evident from Fig. 4, heating at $70^{\circ} \mathrm{C}$ for $30 \mathrm{~min}$ while maintaining the $\mathrm{pH}$ level at 2.0-2.5 was optimum to extract highest \% age of pectin. At this temperature $\left(70^{\circ} \mathrm{C}\right)$, no precipitate of pectin was obtained beyond $\mathrm{pH}$ 4.0 even though the heating time being increased to $3 \mathrm{~h}$. It can be ascertained from the experiment that $\mathrm{pH} 1.0-2.5$ can be the range ( $\mathrm{pH} 2.0$ being the best) where maximum precipitation of pectin was possible at a temperature of $70^{\circ} \mathrm{C}$. With regards to pectin precipitation as a function of heating time, it can be said that $30 \mathrm{~min}$ to $1 \mathrm{~h}$ heating time is sufficient to isolate maximum percentage of pectin as on further increase in heating time did not result in any increase in pectin yield.

Effect of heating at $85^{\circ} \mathrm{C}$, heating times and $\mathrm{pH}$ values on extraction of pectin is shown in Fig. $5 \mathrm{a}$. At this temperature, $\mathrm{pH}$ 1.0-3.0 and $1 \mathrm{~h}$ heating time was

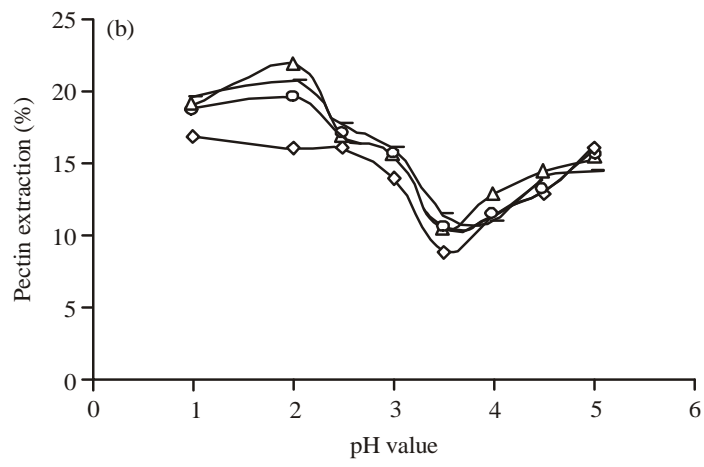

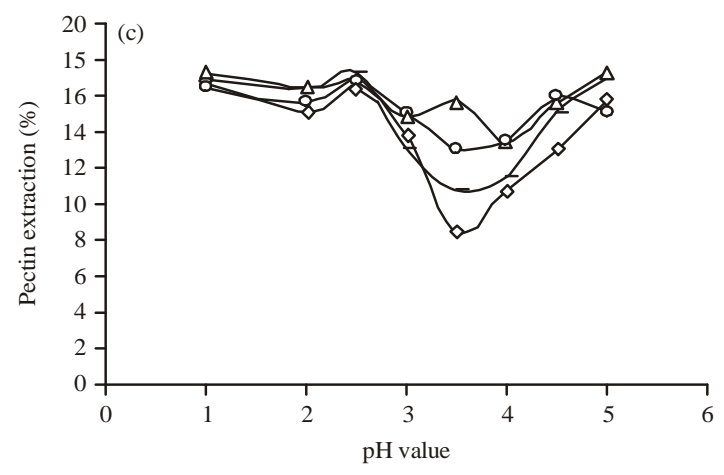

Fig. 5(a-c): Effect of heating, (a) $70^{\circ} \mathrm{C}$, (b) $85^{\circ} \mathrm{C}$ and (c) $95^{\circ} \mathrm{C}$, respectively times and $\mathrm{pH}$ values on extraction of pectin (\%), each value represents average of three determinations 
the optimum condition for maximum percentage extraction of pectin. Heating for one hour at $\mathrm{pH} 2.0$ was the condition where highest percentage of pectin was extracted. It is interesting to note that increase in $\mathrm{pH}$ from 2.0-3.0 resulted in a gradual decrease in percent extraction of pectin at $85^{\circ} \mathrm{C}$. Increasing further $\mathrm{pH}$ value (3.5-5.0) was followed by increase in pectin extraction. At $\mathrm{pH}$ level $5.0,15.32 \%$ pectin was isolated which is comparable to the pectin values obtained with $\mathrm{pH}$ levels 2.5 and 3.0. It is worthy to mention here that the $\mathrm{pH}$ level of slurry obtained by blending citrus peel with distilled water ranged from 4.0-5.0. In this experiment, the best condition for pectin extraction was heating for $1 \mathrm{~h}$ at $\mathrm{pH}$ level 2.0.

Effect of heating $\left(95^{\circ} \mathrm{C}\right)$ times and $\mathrm{pH}$ values on extraction of pectin (\%) are depicted in (Fig. 5b). This is the boiling point of water at Peshawar valley. The highest percent pectin extraction was obtained at $\mathrm{pH} 1.0$ and 5.0 (17.36\%). As for the $85^{\circ} \mathrm{C}$ heating time, percent pectin extraction decreased with increase in $\mathrm{pH}$ level up to 3.5 and thereafter, increased with further increase in $\mathrm{pH}$ value. Percent extraction at $\mathrm{pH}$ level 5.0 was comparable to that of percent extraction at $\mathrm{pH}$ values $1.0-2.5$. It is evident from the data that $\mathrm{pH}$ level 4.5-5.0 is the best $\mathrm{pH}$ range where maximum pectin can be isolated at the boiling temperature. Moreover, $1 \mathrm{~h}$ heating was enough to get maximum extraction.

Most scientific publications have studied the influence of different acid extraction conditions on the chemical characteristics of the extracts from various plant tissues using an experimental design (Levigne et al., 2002; Pagan et al., 2001; Phatak et al., 1988; Robert et al., 2006; Yapo et al., 2007). This statistical approach has allowed the quantification of each parameter and their potential interactions on the extraction yield and chemical characteristics of pectin. In addition, the initial step in the extraction of pectin often involves the preparation of an acetone or alcohol insoluble residue, with the purpose of removing low molecular weight compounds, including any trace of free galacturonic acid. The aim of this step is to remove small molecules (Qi et al., 2000).

Indeed, at constant $\mathrm{pH}$ and temperature, the yields of pectin obtained for $1 \mathrm{~h}$ of extraction were comparable to those for $3 \mathrm{~h}$. Similarly, the pectin yields from various extractions at $\mathrm{pH}$ 1.0-2.5 were higher than those at $\mathrm{pH}$ 3.0-4.0. It was interesting to note that extraction yield at $\mathrm{pH}$ 4.5-5.0 was comparable to that of $\mathrm{pH} 1.0$ to 2.5. Yapo et al. (2007) and Levigne et al. (2002) observed the same trends on pectins extracted from sugar beet, unlike with soy hull pectin where the yields decreased with increasing acid strength (Kalapathy and Proctor, 2001). The total extraction yield reflected the pectin yield but depending on the experimental conditions, some impurities or degraded pectin could have been obtained.
Moreover, Mohamed and Hasan (1995) found a pectin yield (120 $\mathrm{mg} \mathrm{g}^{-1}$ ) from banana peels using other experimental conditions (acetone- $\mathrm{HCl}, \mathrm{pH} 4.0,1 \mathrm{~h}$ and $75^{\circ} \mathrm{C}$ ); this value being in the range of the present study. $\mathrm{pH}$ and time were the most significant interactive effect on the pectin yield. Wang et al. (2014) using subcritical water extracted 21.95 and $16.68 \%$ pectin from citrus peel and apple pomace, respectively.

The suitability of pectins for different purposes is determined by their characters viz., methoxyl content, degree of esterification and acetyl value. Hence, it is an unavoidable aspect that pectin should be described properly for its biochemical characters. If more than 50\% of the carboxyl groups are methylated the pectins are called high-methoxy pectins (HM) and less than that degree of methylation are called Low Methoxy (LM) pectins. This same principal applies also to acetylation (Sharma et al., 2006). High Methoxy (HM) pectins (with $\mathrm{DE}>50 \%$ ) require a relatively high concentration of soluble solids and a low $\mathrm{pH}$ for gel formation (Garna et al., 2004, 2006). Low Methoxy (LM) pectins (with $\mathrm{DE}<50 \%$ ) form rigid gels by the action of calcium or multivalent cat-ions, which cross-link the galacturonic acid chains (Garna et al., 2004).

The Degree of Esterification (DE), which is expressed as a percentage of the esterified carboxyl groups, is an important means to classify pectins. Jams and preserves are of course the main use of industrially extracted pectins. High dissolved sugar and acid conditions ensure that chain-chain interactions dominate over chain-solvent interactions (Sharma et al., 2006). Most chain-chain interactions in these systems are not based on electrostatic interactions and so the other hydrophobic and hydrogen bonding effects exert most influence. High sugar conditions create low water activities which can be mimicked by other solutes with the same resulting gels. This is reflected in the subdivision of HM pectins into rapid-set pectins of DM 77 to slow-set with DM 60. The larger hydrophobic element in HM pectins allows for rapid arrest of the systems.

The characteristics of the extracted pectins varied over a large range depending on the experimental conditions of extractions. The $\mathrm{pH}$ was the main significant factor on yield. Having a large range of DM, these pectins could probably gel with calcium or with high sugar concentrations in acidic condition. By considering the pectin yield, degree of methylation the acid extraction of citrus peels pectin at $\mathrm{pH} 2.0$, for $1 \mathrm{~h}$, at $95^{\circ} \mathrm{C}$ could be suitable. Methoxy content of pectin ranged between $50-70 \%$ depending upon the $\mathrm{pH}$ values employed and heating time. Methoxy content decreased with the increase in $\mathrm{pH}$ value and heating time. Percent acetyle value of pectin was 0.43 . It is reported (Partos, 2005) that 
Sci. Technol. Dev., 34 (1): 9-15, 2015

Table 1: Characterization of pectin extracted from citrus peel

\begin{tabular}{lccr}
\hline Samples & $\begin{array}{l}\text { Methoxy } \\
\text { content (\%) }\end{array}$ & $\begin{array}{l}\text { Acetyl } \\
\text { value (\%) }\end{array}$ & \begin{tabular}{l} 
Viscosity \\
\hline Standardized pectin
\end{tabular} $7^{\mathrm{b}}$ \\
Commercial pectin & $65^{\mathrm{c}}$ & $0.34^{\mathrm{b}}$ & $0.964^{\mathrm{b}}$ \\
Reagent grade pectin & $80^{\mathrm{a}}$ & $0.37^{\mathrm{a}}$ & $0.984^{\mathrm{b}}$ \\
\hline Each value represents average at three determinations, values in the \\
same column with the same letter are not statistically significant (p>5\%)
\end{tabular}

Jams and preserves are of course the main use of industrially extracted pectins. High dissolved sugar and acid conditions ensure that chain-chain interactions dominate over chain-solvent interactions. Most chain-chain interactions in these systems are not based on electrostatic interactions and so the other hydrophobic and hydrogen bonding effects exert most influence. High sugar conditions create low water activities which can be mimicked by other solutes with the same resulting gels. This is reflected in the subdivision of HM pectins into rapid-set pectins of $\mathrm{DM} \sim 77$ to slow-set with $\mathrm{DM} 60$. The larger hydrophobic element in $\mathrm{HM}$ pectins allows for rapid arrest of the systems. As shown in Table 1 the viscosity of our standardized pectin (protopectin) was 0.964 centipoise (cp) which was comparable to that of pectin obtained from SIGMA chemical Company, USA (0.984 cp). Kurita et al. (2008) reported that citric acid treatment of peel at neutral $\mathrm{pH}$ resulted in significant increase in viscosity. However, citric acid treatment at high temperature decreased viscosity of pectin.

\section{CONCLUSION}

It is concluded from this study that heating at $70^{\circ} \mathrm{C}$, for $30 \mathrm{~min}$ and $\mathrm{pH}$ level of 2.0-2.5 were optimum conditions for getting maximum yield of pectin. At this temperature and $\mathrm{pH}>4.0$, pectin could not be obtained. At $85^{\circ} \mathrm{C}$ temperature a higher range of $\mathrm{pH}$ is (1.0-3.0) was required for maximum yield. In this case one hr heating was sufficient to extract most of the pectin; however, heating for 30 min yielded comparable results.

\section{ACKNOWLEDGMENT}

These investigations were partly supported by Pakistan Science Foundation (PSF). We are thankful to Director NIFA for providing facilities to conduct this study.

\section{REFERENCES}

Donaghy, J.A. and A.M. McKay, 1994. Pectin extraction from citrus peel by polygalacturonase produced on whey. Bioresour. Technol., 47: 25-28.
El-Nawawi, S.A. and F.R. Shehata, 1987. Extraction of pectin from Egyptian orange peel. Factors affecting the extraction. Biol. Wastes, 20: 281-290.

Fishman, M.L., H.K. Chau, P. Hoagland and K. Ayyad, 1999. Characterization of pectin, flash-extracted from orange albedo by microwave heating, under pressure. Carbohydrate Res., 323: 126-138.

Garna, H., N. Mabon, B. Wathelet and M. Paquot, 2004. New method for a two step hydrolysis and chromatographic analysis of pectin neutral sugar chains. J. Agric. Food Chem., 52: 4652-4659.

Garna, H., N. Mabon, K. Nott, B. Wathelet and M. Paquot, 2006. Kinetic of the hydrolysis of pectin galacturonic acid chains and quantification by ionic chromatography. Food Chem., 96: 477-484.

Garna, H., N. Mabon, C. Robert, C. Cornet and K. Nott et al., 2007. Effect of extraction conditions on the yield and purity of apple pomace pectin precipitated but not washed by alcohol. J. Food Sci., 72: 1-9.

Kalapathy, U. and A. Proctor, 2001. Effect of acid extraction and alcohol precipitation conditions on the yield and purity of soy hull pectin. Food Chem., 73: 393-396.

Kurita, O., T. Fujiwara and E. Yamazaki, 2008. Characterization of the pectin extracted from citrus peel in the presence of citric acid. Carbohydrate Polymer, 74: 725-730.

Levigne, S., M.C. Ralet and J.F. Thibault, 2002. Characterization of pectins extracted from fresh sugar beet under different conditions using an experimental design. Carbohydrate Polymers, 49: 145-153.

Liu, Y., J. Shi and T.A.G. Langrish, 2006. Water-based extraction of pectin from flavedo and albedo of orange peels. Chem. Eng. J., 120: 203-209.

Mohamed, S. and Z. Hasan, 1995. Extraction and characterisation of pectin from various tropical agrowastes. ASEAN Food J., 10: 43-50.

Pagan, J., A. Ibarz, M. Llorca, A. Pagan and G.V. Barbosa-Canovas, 2001. Extraction and characterization of pectin from stored peach pomace. Food Res. Int., 34: 605-612.

Partos, L., 2005. A first, pectin ingredient enters Cargill's portfolio. July 15, 2005. http://www.foodnavigator. com/Market-Trends/A-first-pectin-ingredient-entersCargill-s-portfolio

Phatak, L., K.C. Chang and G. Brown, 1988. Isolation and characterization of pectin in sugar beet pulp. J. Food Sci., 53: 830-833.

Qi, B., K.G. Moore and J. Orchard, 2000. A comparison of two methods and the effect of cooking time on the extractability of pectin from the cell walls of cooking banana. LWT-Food Sci. Technol., 33: 369-373. 
Robert, C., T. Devillers, B. Wathelet, J.C. Van Herck and M. Paquot, 2006. Use of a Plackett-Burman experimental design to examine the impact of extraction parameters on yields and compositions of pectins extracted from chicory roots (Chicorium intybus L.). J. Agric. Food Chem., 54: 7167-7174.

Sharma, B.R., L. Naresh, N.C. Dhuldhoya, S.U. Merchant and U.C. Merchant, 2006. An overview on pectins. Times Food Process. J., 23: 44-51.
Wang, X., Q. Chen and X. Lu, 2014. Pectin extracted from apple pomace and citrus peel by subcritical water. Food Hydrocolloids, 38: 129-137.

Yapo, B.M., C. Robert, I. Etienne, B. Wathelet and M. Paquot, 2007. Effect of extraction conditions on the yield, purity and surface properties of sugar beet pulp pectin extracts. Food Chem., 100: 1356-1364. 